\title{
Recommendations for the Treatment of Systemic Sclerosis: Agreement May Not Translate into Uptake
}

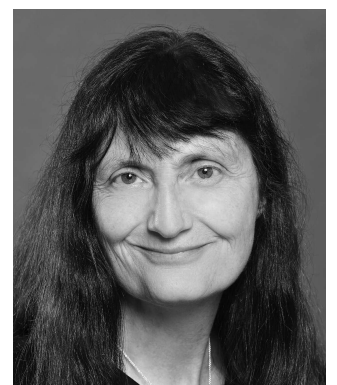

In this issue of The Journal, de Vries-Bouwstra, et al evaluated the level of agreement for the recommendations for systemic sclerosis (SSc; scleroderma) treatment from the European League Against Rheumatism (EULAR) Scleroderma Trials and Research group (EUSTAR $)^{1,2}$. They studied the level of agreement on an 11-point scale (from 0 no agreement, to 10 full agreement) and surveyed $481 \mathrm{SSc}$ experts from various organizations, most of whom had more than a decade of experience in the treatment of SSc. The response rate was about $55 \%$, reasonable for this type of survey ${ }^{1}$. They found most items had a high level of agreement. Not surprisingly, there was high agreement in areas beyond debate, such as treating scleroderma renal crisis with angiotensin-converting enzyme inhibitors, and using proton pump inhibitors to treat symptoms of gastroesophageal reflux disease (GERD) and prevent GERD complications. There was also high agreement that patients with SSc who were using corticosteroids should have blood pressure and renal function monitored. This would be especially important in the diffuse cutaneous SSc (dcSSc) subset who are positive for anti-RNA polymerase antibody ${ }^{3}$, but many laboratories do not measure this antibody. The lowest agreement was for treatment of Raynaud phenomenon (RP) with fluoxetine, and this may be due to the low likelihood of efficacy with this treatment. Only 1 trial supports its use. The other areas where agreement was fewer than 8 of 10 included stem cell transplantation for selected $\mathrm{dcSSc}$ patients with rapidly progressive organ failure risk, RP treatment with phosphodiesterase (PDE)-5 inhibitors or intravenous iloprost, bosentan for multiple digital ulcers to prevent new ones, and riociguat for treatment of pulmonary arterial hypertension (PAH). All this disagreement may be due to access issues. The use of methotrexate to improve skin condition also had agreement $<8$, even though it is widely available and has some trial data ${ }^{3,4}$; this may reflect a desire for better improvement in skin than what is expected with this treatment.
Expert agreement for the previous SSc recommendations published in 2009 was studied and did demonstrate regional differences regarding endorsement of specific recommendations likely related to access differences, such as iloprost intravenously and bosentan for prevention of recurrent digital ulcers, where these agents are approved in Europe and not North America for the indications ${ }^{5,6}$.

Also, agreement among expert-created algorithms for organ-based treatment of SSc has increased over time, as shown by publications on first-line and further therapy in $\mathrm{SSc}^{7,8}$. PDE-5 inhibitors for significant RP in SSc were ranked early in the RP treatment algorithm but had less agreement in the current study ${ }^{1}$.

Some of the recommendations with the lowest agreement [selective serotonin reuptake inhibitor (SSRI) use in RP, riociguat for $\mathrm{PAH}$ in $\mathrm{SSc}$, and autologous hematopoietic stem cell transplant (HSCT)] were new compared to the 2009 recommendations ${ }^{1,2,5}$. Perhaps experts have not added the treatment into their practice or the generalizability is low to their practice (very few patients are eligible for HSCT). In addition, physicians may lack experience with HSCT, or there may be concern about the elevated mortality in the first year after HSCT. Other possibilities are inexperience with prescription of SSRI for RP, or uncertainty about its efficacy.

This current study may not be generalizable to others who treat SSc for several reasons ${ }^{1}$. The study asked experts in $\mathrm{SSc}$, most of whom are rheumatologists - a practice that may not reflect opinions of non-experts who treat SSc in their practices and others who treat SSc including respirologists/pulmonologists, cardiologists, and gastroenterologists . One-fifth of respondents were not part of an official SSc network; a third were not rheumatologists and half cared for 50 or fewer patients with SSc in the last 6 months. The 2 groups, however, had similar agreement, except that rheumatologists agreed more with the guidelines than non-rheumatologists, perhaps because the guidelines were written mostly by rheumatologists and published in a major rheumatology

See Recommendation agreement in SSc, page 249

Personal non-commercial use only. The Journal of Rheumatology Copyright @ 2020 . All rights reserved. 
journal. The respondents were primarily from Europe; however, about $30 \%$ were from other continents.

Some of the respondents were authors of the guidelines, so they would be expected to have high agreement. They were not compared to others who answered the survey, because the results were anonymous. It would be interesting to see whether agreement was different between those who participated in the guidelines and the others.

Agreement with guidelines does not necessarily translate into practice. For instance, only about half of guidelines are routinely followed ${ }^{9,10}$. Site differences among Canadian rheumatologists who enrolled their patients in an SSc registry have been observed in screening and treatment ${ }^{10,11,12}$.

Care is a moving target, especially as new trial data become available, such as for the treatment of interstitial lung disease (ILD) in SSc. As examples, nintedanib for the treatment of progressive pulmonary fibrosis in SSc-associated ILD has yielded positive results ${ }^{13,14}$, and the Scleroderma Lung Study III ${ }^{15}$ will compare pirfenidone with mycophenolate mofetil (MMF) versus MMF alone. There are advances in PAH whereby the results of initial treatment with 2 PAH drugs versus 3 will be reported within a year ${ }^{16}$. Guidelines will usually lag behind the trials and changes are added when updates to recommendations are done. A further lag occurs before there is translation into practice because that requires access to medications, resulting in a trickling down of experience that often starts at expert sites and disseminates to other rheumatologists.

There is high agreement mostly among SSc experts for many of the 2017 recommendations for SSc management, despite some variability by continent. Agreement by experts does not generalize to the majority of practicing rheumatologists and may far overestimate actual care through practice audits.

JANET E. POPE (D), MD, MPH, Schulich School of Medicine, University of Western Ontario, St. Joseph's Health Care, London, Ontario, Canada.

Address correspondence to Dr. J.E. Pope, Division of Rheumatology, St. Joseph's Health Care, 268 Grosvenor St., London, Ontario N6A 4V2, Canada.E-mail: janet.pope@sjhc.london.on.ca

\section{REFERENCES}

1. de Vries-Bouwstra J, Allanore Y, Matucci-Cerinic M, Balbir-Gurman A. Worldwide expert agreement on updated recommendations for the treatment of systemic sclerosis. J Rheumatol 2020; 47:249-54.

2. Kowal-Bielecka O, Fransen J, Avouac J, Becker M, Kulak A, Allanore Y, et al. Update of EULAR recommendations for the treatment of systemic sclerosis. Ann Rheum Dis 2017;76:1327-39.
3. Pope JE, Bellamy N, Seibold JR, Baron M, Ellman M, Carette S, et al. A randomized, controlled trial of methotrexate versus placebo in early diffuse scleroderma. Arthritis Rheum 2001;44:1351-8.

4. van den Hoogen FH, Boerbooms AM, Swaak AJ, Rasker JJ, van Lier HJ, van de Putte LB. Comparison of methotrexate with placebo in the treatment of systemic sclerosis: a 24 week randomized double-blind trial, followed by a 24 week observational trial. Br J Rheumatol 1996;35:364-72.

5. Kowal-Bielecka O, Landewe R, Avouac J, Chwiesko S, Miniati I, Czirjak L, et al. EULAR recommendations for the treatment of systemic sclerosis: a report from the EULAR Scleroderma Trials and Research group (EUSTAR). Ann Rheum Dis 2009;68:620-8.

6. Walker K, Pope J, Scleroderma Clinical Trials Consortium (SCTC), Canadian Scleroderma Research Group (CSRG). Expert agreement on EULAR/EUSTAR recommendations for the management of systemic sclerosis. J Rheumatol 2011;38:1326-8.

7. Fernández-Codina A, Walker KM, Pope JE; Scleroderma Algorithm Group. Treatment algorithms for systemic sclerosis according to experts. Arthritis Rheumatol 2018;70:1820-8.

8. Walker K, Pope J. Treatment of systemic sclerosis (SSc) complications: what to use when first-line treatment fails. A consensus of SSc experts. Semin Arthritis Rheum 2012;42:42-55.

9. McKeown E, Bykerk VP, De Leon F, Bonner A, Thorne C, Hitchon $\mathrm{CA}$, et al; CATCH Investigators. Quality assurance study of the use of preventative therapies in glucocorticoid-induced osteoporosis in early inflammatory arthritis: results from the CATCH cohort. Rheumatology 2012;51:1662-9.

10. Reed J, Pope JE. A comparison between general rheumatologists and scleroderma experts with respect to following systemic sclerosis guidelines. Clin Exp Rheumatol 2015;33 (4 Suppl 91):S40-6.

11. Pope J, Harding S, Khimdas S, Bonner A; Canadian Scleroderma Research Group, Baron M. Agreement with guidelines from a large database for management of systemic sclerosis: results from the Canadian Scleroderma Research Group. J Rheumatol 2012; 39:524-31.

12. Harding S, Khimdas S, Bonner A; Canadian Scleroderma Research Group, Baron M, Pope J. Best practices in scleroderma: an analysis of practice variability in SSc centers within the Canadian Scleroderma Research Group (CSRG). Clin Exp Rheumatol 2012;2 Suppl 71:S38-43.

13. Distler O, Brown KK, Distler JHW, Assassi S, Maher TM, Cottin V, et al. Design of a randomised, placebo-controlled clinical trial of nintedanib in patients with systemic sclerosis-associated interstitial lung disease (SENSCISTM). Clin Exp Rheumatol 2017;35 Suppl 106:75-81.

14. Distler O, Highland KB, Gahlemman M, Azuma A, Fischer A, Mayes MD, et al; SENSCIS Trial Investigators. Nintedanib for systemic sclerosis-associated interstitial lung disease. N Engl J Med 2019;380:2518-28.

15. Scleroderma Lung Study III - combining pirfenidone with mycophenolate (SLSIII). [Internet. Accessed August 9, 2019.] Available from: clinicaltrials.gov/ct2/show/NCT03221257

16. The efficacy and safety of initial triple versus initial dual oral combination therapy in patients with newly diagnosed pulmonary arterial hypertension (TRITON). [Internet. Accessed August 9, 2019.] Available from: clinicaltrials.gov/ct2/show/NCT02558231

J Rheumatol 2020; 47:164-5; doi:10.3899/jrheum.190582 